\title{
Irregular Development in the Larval History of Meganyctiphanes norvegica.
}

\author{
By \\ Roderick Macdonald, M.A., B.Sc., \\ Research Fellow, The Marine Biological Station, Millport
}

With 1 Figure in the Text and 1 Plate.

THE object of this paper is to draw attention to some irregularities in the larval development of Meganyctiphanes norvegica. Sars (1898) described a Euphausid larval development which he said would seem to refer to two forms, viz. Nyctiphanes norvegicus and Boreophausia raschii, which both at times occur rather abundantly in the Christiania Fjord. These Euphausids, now known as Meganyctiphanes norvegica and Thysanoessa raschii respectively, are also found occasionally associated in large numbers in certain parts of the Clyde Sea Area. In individual lochs, however, though contiguous, one species generally occurs much more abundantly than the other, e.g. $M$. norvegica is the predominating species in Upper Loch Fyne, whereas T. raschii is the more numerous in Loch Striven. Both species are found in Loch Goil and Loch Long, where T. raschii is again the more common. In all cases the largest numbers of adults are found from mid-September to mid-March. The doubt expressed above by Sars has been cleared, and I have been able to distinguish the life histories of these Euphausids from the unsegmented egg to the mature adult.

The life history of $M$. norvegica fits in with that described by Sars (1898) and Lebour (1925), with, however, the following interesting differences. The eggs found in the Clyde Sea Area have not only a wider range in size (the diameter of the outer shell measuring $\cdot 59-85 \mathrm{~mm}$.), but two different types of nauplii are produced. The smaller type of nauplius agrees with that described by Sars, and arises from eggs the diameter of whose outer shell measures $\cdot 59-70 \mathrm{~mm}$. The larger type of nauplius which apparently is now described for the first time, comes from eggs whose outer shell diameter measures $\cdot 65-\cdot 85 \mathrm{~mm}$. In all the sizes of eggs the young embryo which measures ca. $\cdot 40 \mathrm{~mm}$. is tinged (towards the abapical pole) with a distinctive salmon pink colour. The colouring becomes more intense as segmentation proceeds. All the nauplii, whether before or after hatching, have their posterior ends tinged with this colour. 
The larger nauplius arises as follows: Segmentation and gastrulation takes place, as described by Sars. The limbs of the developing nauplius are laid down (Plate I, Fig. 1), and ultimately the nauplius is formed (Plate I, Fig. 2). It is somewhat elongated, and measures $42 \mathrm{~mm}$. in length and $\cdot 30 \mathrm{~mm}$. at its greatest breadth. The nauplius still within the outer shell becomes larger, $\cdot 48 \mathrm{~mm}$. in length and $\cdot 32 \mathrm{~mm}$. at its greatest breadth, and narrowed posteriorly (Plate I, Fig. 3). During the enlargement of the nauplius while still in the shell no sloughing of a naupliar skin was observed, although it will be seen that distinct alteration in form has taken place.

On emerging from the shell the nauplius takes the form seen in Plate I, Fig. 4, and measures $53 \mathrm{~mm}$. long by $\cdot 32 \mathrm{~mm}$. at its greatest breadth. The anterior end is broad and somewhat truncated, whereas the posterior end is more or less pointed. As development proceeds the metanaupliar form is prefigured below the outer skin and we may have either of two forms produced, the second nauplius having either the form indicated in Plate I, Fig. 5 or, on the other hand, showing at its posterior end six spines, four short and two long, as depicted in Plate I, Fig. 6. The second nauplius measures $.55 \mathrm{~mm}$. in length and .33 at its greatest breadth. An ocellus is present, and there is also a foreshadowing of the ocular plate seen in the metanauplius, from which the compound eyes develop in the later larvæ. Traces of three pairs of limbs which become free buds in the metanauplius are indicated as are also the mouth and anus. The metanauplius differs only in size, measuring $\cdot 62 \mathrm{~mm}$., from that derived from the smaller nauplius, and described by Sars and Lebour. The telson of the metanauplius is shown (Plate I, Fig. 7). In the Clyde Sea Area

\section{EXPLANATION OF PLATE I.}

Meganyctiphanes norvegica.

1-3 (all drawn to same scale).

Fia. 1.-Egg with developing nauplius. Egg, $.67 \mathrm{~mm}$. in diameter.

Frg. 2.-Egg with nauplius further developed than in Fig. 1.

Egg, $.72 \mathrm{~mm}$. in diameter. Nauplius, $42 \mathrm{~mm}$. long.

FIG. 3.-Egg with nauplius further developed than in Fig. 2.

Egg, $.85 \mathrm{~mm}$. in diameter. Nauplius, $48 \mathrm{~mm}$. long.

4-7 (all drawn to same scale).

Frg. 4.-First nauplius from egg $.53 \mathrm{~mm}$. long, ventral view.

Frg. 5.-Second nauplius from first nauplius, $.55 \mathrm{~mm}$. long, ventral view.

Fig. 6.-Posterior end of body as it appears in the other form of second nauplius, which arises from first nauplius, ventral view.

Fig. 7.-Telson of metanauplius, dorsal view. 
PLATE I.

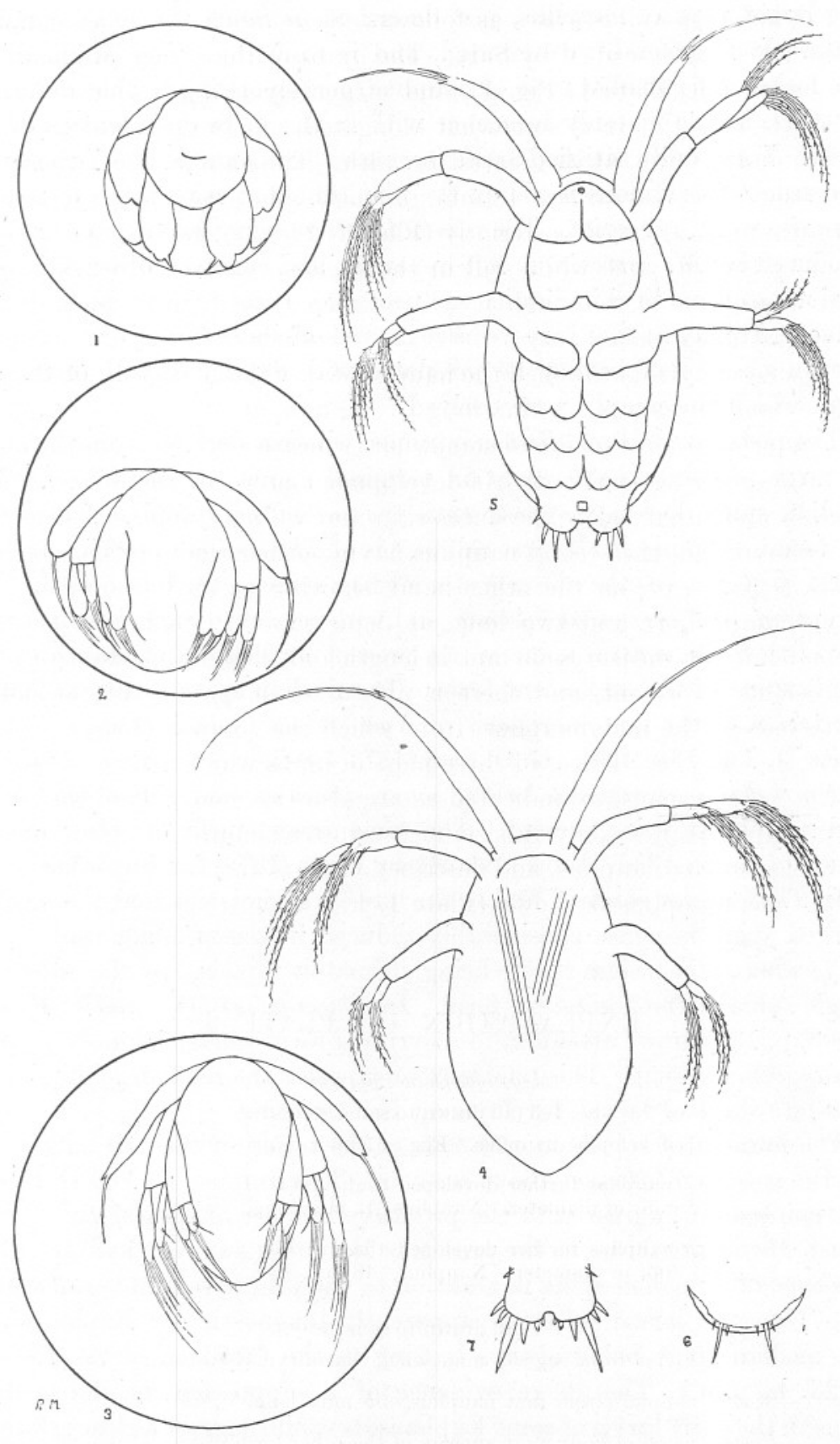


the larger type of nauplius, just described, is much the more common form. It is generally distributed, and is sometimes very abundant in the lochs. The smaller type of nauplius, corresponding to that described by Sars, has so far only been met with in the more open waters of the Area. I am quite satisfied from rearing experiments in the Laboratory and from observations made on the plankton that both types of nauplii give rise to $M$. norvegica. The reason for there being two types of nauplii produced by $M$. norvegica is not apparent, and constant observations at various stations in this district are necessary before the problem can be solved. It may be that here we have in-and off-shore forms, or that variation in size of nauplii may be correlated with density of yolk of the egg from which the nauplii were derived.

The metanauplius and first calyptopis, whether derived from the small or large nauplius, have each six terminal spines on the telson. The median spine does not appear until the second calyptopis. I also find six terminal spines in the first calyptopis of Thysanoessa raschii. Lebour $(1924$, p. 4) records the absence of a median spine in the telson of the first calyptopis of Thysanoessa inermis, and with regard to Stylocheiron suhmii states that the central spine is not present until the appearance of the single spine of the adolescent form. The median spine is also absent in the telson of the first calyptopis of Nyctiphanes Couchii (Lebour, 1924 ; Plate II, Fig. 1, p. 423). G. O. Sars (1873-76) figures the first calyptopis of Nyctiphanes australis as having seven spines on each side of the telson and no median spine present. The same arrangement of spines on the telson of the first calyptopis is shown by Claus (1876) for Euphausia.

In Thysanoessa raschii I find in the late cyrtopia larvæ that the median. jointed spine becomes considerably reduced in size, though there is no stage where it is absent, before being ultimately replaced by the unjointed single spine of the adolescent form. In Thysanoessa longicaudata Fowler (1903, p. 130) draws attention to a cyrtopia form where the median spine is altogether absent. This tendency to suppress the median jointed spine in a late stage of larval development is interesting.

The number of spines on each side of the telson of the first calyptopis for the species mentioned above is seven. This number, as Fowler (1903) has pointed out, agrees with the primitive number of spines, viz. $(7+7)$, which Meyer attributes to the primitive Macruran and Brachyuran. The presence of a median spine in addition to the primitive number of spines $(7+7)$ on the larval telson is apparently diagnostic for Euphausiidæ, the median spine being always lacking in the Caridean larvæ, Lebour (1926, b, p. 4.) The above evidence of a suppression of the median spine in the early larvæ of some Euphausids would suggest a close relationship between the Euphausiida and primitive Decapods.

I have been unable to detect any anatomical difference in the meta- 
nauplius and calyptopis stages from that described by Lebour (1925). While this is true I have found evidence of interesting modifications and variations in the development of the furcilia forms. The furcilia are distinguished as follows: (1) eyes are no longer covered by the carapace ; (2) the appearance of the pleopods. The sequence of the appearance of the latter has been used to distinguish successive stages in the development as follows :-

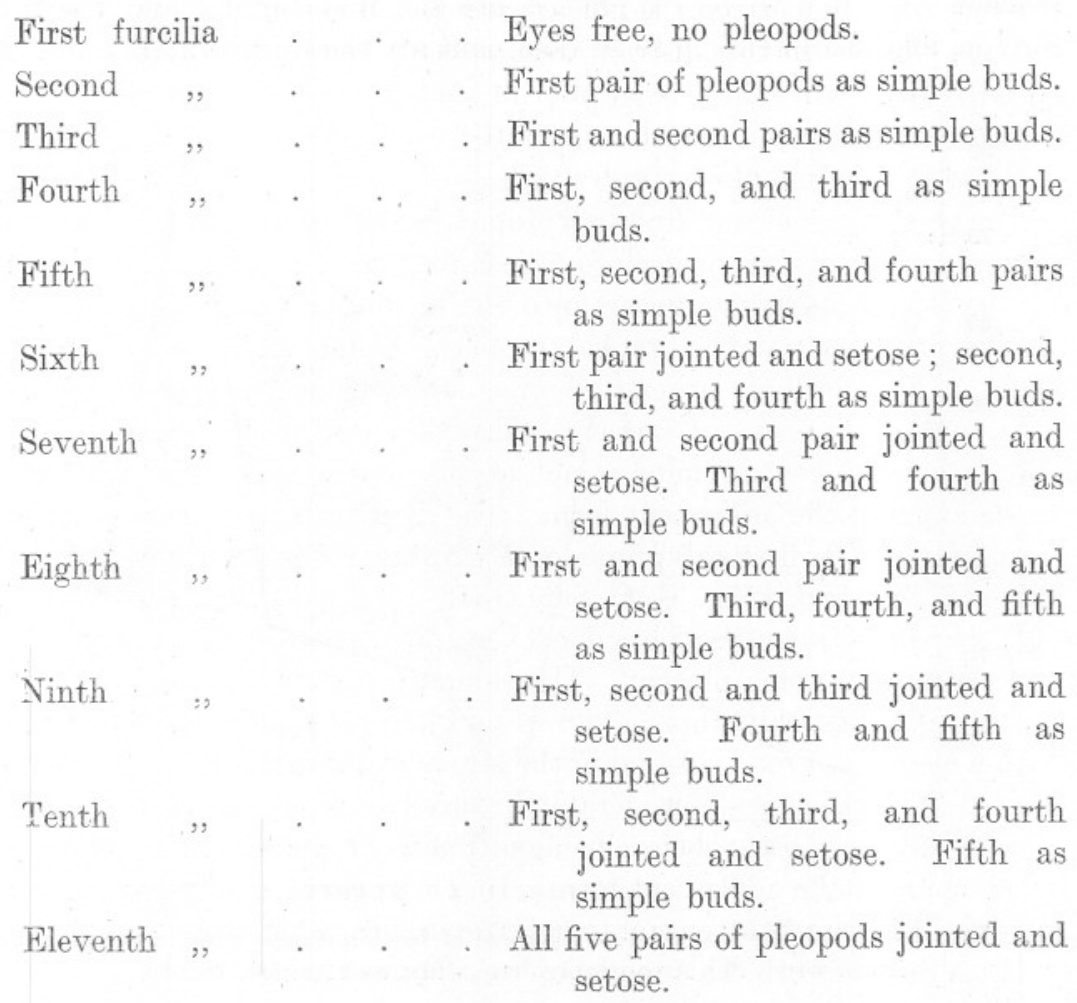

In June, 1925, while examining a furcilia, corresponding to the fourth stage above, under the binocular the specimen moulted, and now obviously belonged to the sixth stage instead of the fifth. Later a typical fifth furcilia stage was found in the plankton, and accordingly it was decided to make a closer study of these so-called stages by rearing experiments in the Laboratory. During the summer of 19261 had several opportunities of studying larvæ of $M$. norvegica in captivity, and although there was a large mortality, was successful in bringing some of them through one or two moults. The result of the work showed that in the development of the furcilia forms certain stages tend to be dominant and others to be suppressed. In other words, there is a tendency to reduce 
the number of larval stages. I also found that those furcilia stages which were observed to be sometimes omitted during development in captivity were less frequent in the plankton than the other furcilia stages. On the other hand, there were certain stages which predominated in numbers in the plankton (see Text Fig. 1). Unfortunately the amount of material available was not as large as was desired, but from the examination of 302 furcilia specimens it is found that the stages with the best marked tendency to be suppressed are the first furcilia and the fifth furcilia, and those tending to be dominant are the fourth furcilia and the

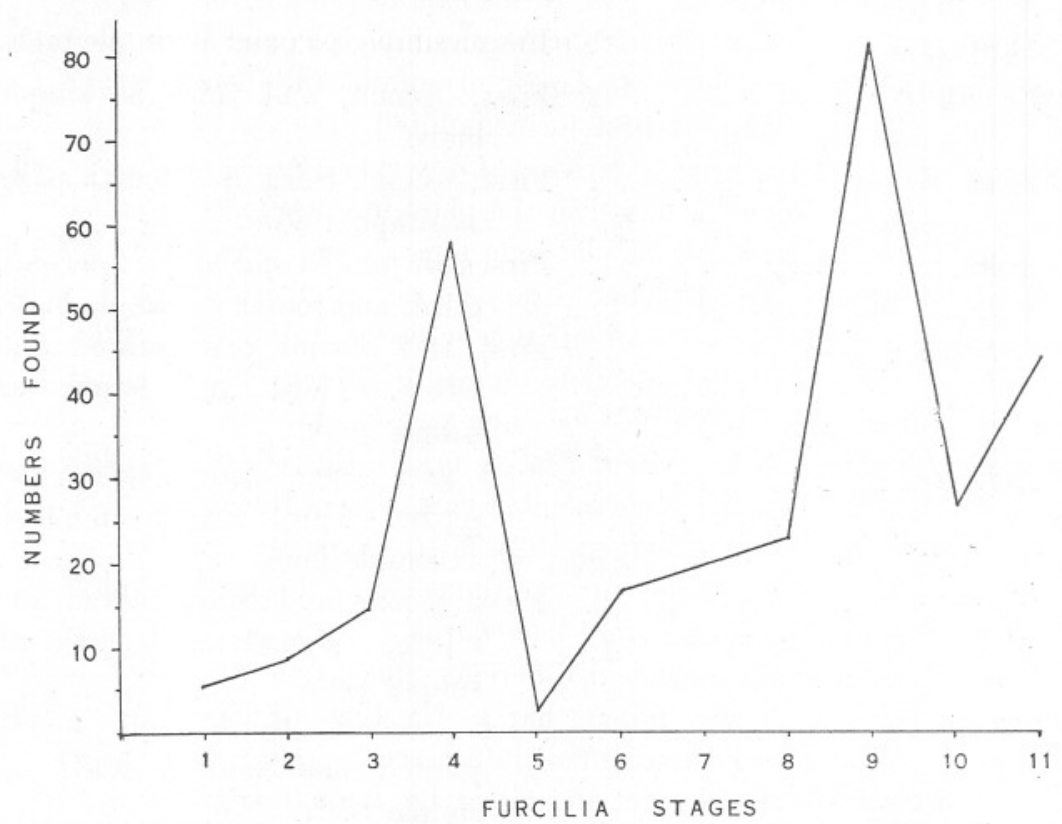

Texт Fig. 1.-Graph showing relative numbers of furcilia stages found in the plankton in the Clyde Sea Area during June, July, and August, 1926.

ninth furcilia. Specimens were taken from the plankton, and placed in glass vessels, each containing 500 c.c. of sea-water. The glass vessels were kept in diffuse daylight in running water whose average temperature was ca. $12 \cdot 9^{\circ} \mathrm{C}$. The results are indicated in the following table :--

No. which moulted irregularly.

No. of

specimens No. which 3rdCalyptopis 3rdCalyptopis 2nd Furcilia 4th Furcilia 4th Furcilia 7th Furcilia which moulted moulted 3rd to to to to to to to to to successfully. regularly. 2nd Furcilia. 3rd Furcilia. 4th Furcilia. 6th Furcilia. 7 th Furcilia. 9th Furcilia.

$\begin{array}{llllllll}26 & 12 & 3 & 2 & 3 & 1 & 2 & 3\end{array}$

Mr. Elmhirst has shown me records made by him of cases in which a furcilia jumped from stage four to stage nine, and from stage two to stage 
four. Again Lebour (1925, p. 813) records a third calyptopis giving rise to a second furcilia. Among specimens of the fourth furcilia stage two forms can be distinguished, one having all three pairs of simple buds of the same size, another having the third pair of simple buds half as long as the first two pairs, neither of the latter being setose. On one occasion, however, a specimen was found in the plankton, having the first pair of pleopods setose and two pairs as simple buds. This particular stage is said to be characteristic of Stylocheiron suhmii (Lebour, 1926 (a), p. 205). This stage, however, appears to be of rare occurrence, as I have not been able to find another of the same. Two forms can also be distinguished in the ninth stage, one form having both pairs of simple pleopod buds the same size, the other having the second pair of simple buds smaller than the first pair. In this case the first form moulted in captivity to give the second form. One other irregularity was observed. On several occasions the following specimens occurred in the plankton: seventh furcilia with left member of second pair of pleopods non-setose; seventh with right member of second pair of pleopods non-setose ; eighth furcilia with left member of second pair of pleopods non-setose; ninth furcilia with left member of second pair of pleopods non-setose; eleventh furcilia with left member of fifth pair of pleopods non-setose. Two interesting points may be noted: (1) the irregularity is practically consistent, since in almost every case it is the same member (viz. left) of the last pair of pleopods formed that is undeveloped. (2) There is an apparent metameric progression of an irregularity in accordance with the usual sequence of development, that is from before backwards.

With regard to morphological differences for particular stages as described by Lebour, it was noted that in the forms I have studied the thoracic appendages and abdominal luminescent organs develop earlier. Development agrees with that described by Lebour (1925, p. 823), in so far as the first thoracic appendage is well formed in all stages. With regard to the appearance of the other thoracic appendages, thoracic and abdominal luminescent organs, I find the following :-

Sixth furcilia . . . . . Second thoracic appendage is jointed.
Eighth* $\quad$ Luminescent organ on first abdominal
segment.

* The luminescent organ on first abdominal segment may not be present till the ninth furcilia, but so far as I have found it is never later in appearing. 
Tenth furcilia

Eleventh ,
Third thoracic appendage jointed with non-setose exopod and onelobed gill. Fourth and fifth appendages as buds.

Third thoracic appendage, five jointed with setose exopod. Fourth appendage unjointed. Luminescent organ present on seventh appendage, which has a twolobed gill.

The stage following this is the first cyrtopia where all the luminescent organs are present. According to Lebour there are twelve furcilia stages, and the appearance of luminescent organs and development of thoracic appendages are described as follows :-

Ninth furcilia . . . Second thoracic leg jointed, third and fourth unjointed with rudimentary gills. No luminous organ except on eyes.

Tenth ". . . . About the same size as the ninth.
Eleventh , . Much like the twelfth, but smaller
and not quite so far advanced
with regard to appendages.

Twelfth " . . . Second thoracic leg five-jointed with setose exopod and two-lobed gill and with luminous organ; third leg five-jointed with non-setose exopod and no gill, fourth leg unjointed with two terminal setæ, exopod, and no gill, fifth limb rudimentary; three abdominal luminous organs.

First cyrtopia . . All luminous organs present, those on the seventh thoracic being not quite perfect.

From the above observations it would appear that during the development of $M$. norvegica in the Clyde Sea Area the furcilia period is one of instability, and that we have here evidence of an incipient shortening of the larval existence by the numerical reduction of instars in addition to a hastening of development by the earlier appearance of the luminescent organs and growth of the thoracic appendages (Macdonald, 1926). 
Recently evidence of curtailed larval history has been found with regard to other species of Euphausids, where the omission of particular stages would appear to have gone farther than that found in $M$. norvegica. Concerning Nematoscelis microps, Lebour states (1926, p. 766): "The youngest stage found is presumably the second furcilia, measuring $2.4 \mathrm{~mm}$. in length, and having one pair of simple bud-like pleopods. . . . The next seen has one pair of pleopods setose and three pairs simple, presumably the sixth furcilia . . measuring $2 \cdot 7 \mathrm{~mm}$. in length. These two stages correspond with the second and sixth furcilia of Nyctiphanes and Meganyctiphanes, but it is conceivable that intermediate stages are skipped. It is striking that these stages, together with the tenth, seem to be dominant as no intermediate stages were found, whilst these were abundant. Moreover, the sixth and tenth are the stages described by Hansen and Sars."

Again (p. 770) with reference to Euphausia krohnii, "Sars describes the second and seventh furcilia having one pair of simple pleopods, and one pair setose with four pairs simple respectively. Curiously enough no stages between these two have been found in the Alexandria samples, although many specimens of both these stages occurred. Possibly this is again a case of jumping over several stages which was suggested above for Nematoscelis."

Among Crustacea continuous larval development is considered a primitive feature, whereas a marked metamorphosis is characteristic of more highly developed forms (Gurney, 1924, p. 48). For this reason the above observations are interesting, as they suggest tentative steps in an evolutionary progress in the order Euphausiaceæ towards reduction in number of larval stages. They also suggest that in those Arthropods in which the life history consists of a few pronounced stages these are to be regarded not as having evolved independently from a continuous life history, but rather as the survivors of a once greater number of successive yet distinct stages.

I am indebted to Professor Graham Kerr, F.R.S., for helpful advice, and to Mr. Elmhirst who so very kindly put his records and material at my disposal.

\section{SUMMARY.}

A new type of Nauplius belonging to Meganyctiphanes norvegica is described.

Attention is drawn to irregularities in the development of the furcilia forms in which particular stages are sometimes omitted.

It is suggested that in the larval history of $M$. norvegica in common with other Euphausids there is an indication of evolutionary progress in the group Euphausiaceæ. 


\section{LITERATURE.}

Claus, C. 1876. Untersuch. Crustaceen-Systems, Pl. I, Fig. 2.

Gurney, R. 1924. Terra Nova Expedition, 1910. Crustacea, Part IX. Decapod Larvæ.

Lebour, M. V. 1925. The Euphausiidæ in the Neighbourhood of Plymouth. Journ. Mar. Biol. Assoc., Vol. XIII, No. 4 (October).

Lebour, M. V. 1926. On Some Larval Euphausiids from the Mediterranean in the Neighbourhood of Alexandria, Egypt. Proc. Zool. Soc., London (September).

Lebour, M. V. 1926 (a). The Young of Stylocheiron suhmii, G. O. Sars, and Stylocheiron abreviatum, G. O. Sars (Crustacea). Proc. Zool. Soc., London (April).

Lebour, M. V. 1926 (b). The Euphausiidæ in the Neighbourhood of Plymouth. III. Thysanoessa inermis. Jour. Mar. Biol. Assoc. Vol. XIV, No. 1 (March).

Macdonald, R. 1926. Numerical Reduction of instars in the Metamorphosis of Euphausids. "Nature," Vol. 117, No. 2956, p. 894, June 26th.

Sars, G. O. 1898. The Propagation and Early Development of Euphausiidæ. Archiv for Mathematik og Naturvidenskab. B. XX, Nr. 11.

Sars, G. O. 1873-76. Chall. Rep. Zool., XIII. Schizopoda, Pl. XXVIII, Fig. 6. 